\title{
DEVELOPMENT OF SPORT TOURISM ATTRACTION IN SMALL TOWN
}

\author{
Rohaizah Abd Latif and Ak Muhammad Azmi Pg Hj Zainal Abidin \\ UNITAR International University, Selangor, Malaysia
}

\begin{abstract}
The purpose of this research is to study the development of sport tourism based attraction. The development of the tourism attraction will compliment economic development and socio-cultural development in the area. It also assess on the impact of ecosystem and environmental pollution in the area. Data were collected by using qualitative approach, interview and observation which gave a significant result on the issue investigated. This findings will benefit the industry by pointing out the potential problems as well as giving solutions and recommendations towards developing a sport tourism attraction.
\end{abstract}

Key words: development, sport tourism attraction, economic and socio cultural development, ecosystem impact.

Cite this Article: Rohaizah Abd Latif and Ak Muhammad Azmi Pg Hj Zainal Abidin, Development of Sport Tourism Attraction in Small Town, International Journal of Management, 11(12), 2020, pp 449-456.

http://iaeme.com/Home/issue/IJM?Volume=11\&Issue=12

\section{INTRODUCTION}

Tasik Biru Kundang is located at Kampung Melayu Sri Kundang which is located in subdistrict of Rawang and it is about 25 kilometres north from Kuala Lumpur. The history to the lake started off as a tin mining ore with the depth of 18.3 metres as well as a six years' operation before its abandonment. The lake's name of Tasik Biru or Blue Lake is named after a colour due to the distinct colour cause by the depth of the lake itself.

The history of public park development in Malaysia started with the British administration by introducing Kuala Lumpur Lake Garden in 1890's, the Penang Botanical Garden in 1844 and Taiping Lake Garden in 1897. The idea of Public Park continues after the country's independence where several public parks being introduced which are Taman Tasik Titiwangsa, Taman Tasik Permaisuri, Taman Tasik Shah Alam and many more. Water sports development in the area may be effective to pull sports enthusiast to the lake. The only current available activity is jet-skiing but the operation timing is inconsistent. Further development to other areas of attraction could attract more visitors. This was in conjunction with the Malaysian Government movement towards an urban renewal where several policies were 
made to upgrade the living environment (Abu Bakar 2002). Normally people will go to an open space or public park, to do various recreational activities (Bilgili and Gökyer, 2012). While the lake has its own popularity amongst the local, it is quite hidden from majority of the population due to the lack of advertising on the lake. Developing the lake into a water sports tourism area may bring in visitors. Potential problems such as pollution may arise from the quality of the lake, the air in the area and the ecosystem of animals and plants in the area. Pollution from jet-skiing could also cause a problem for the lake. Jet-skiing emits fuel and carbon monoxide which could further disrupt the water $\mathrm{pH}$ (potential of Hydrogen) value of the water in the lake which could make it unsafe for swimming and it could further harm the ecology in the lake. Developing the lake could meant that an increase of wastage could pollute the area. the increasing visitors could mean that more garbage could be thrown in the area. Maintenance needs to be maintained around the lake in order to keep the area clean.

The research was conducted with the following objectives; (1) To develop Tasik Biru Kundang a new tourist destination and attraction to compliment economic development and socio-cultural impact, (2) To explore the stature of ecosystem at Tasik Biru Kundang, and (3) To identify the impact of environmental pollution at Tasik Biru Kundang.

The research was conducted to answer the following research questions; (1) How are the developments at Tasik Biru Kundang as a new tourist destination and attraction done to compliment economic development and socio-cultural impacts?, (2) What are the stature of ecosystem at Tasik Biru Kundang? and, (3) Are there any impact of environmental pollution present at Tasik Biru Kundang?

This study can benefit the industry by pointing out all potential problems as well as giving solutions and recommendations towards developing Tasik Biru Kundang as a tourist destination. This development could help the local community in terms of their economy especially for restaurant owners. For academia, this research could help for future research in sectors that were not covered. This could also help as a literature for future research done on other lakes for their study. The site could also be used by future researchers to gather and collect information.

\section{LITERATURE REVIEW}

Sports tourism is defined as a personal travel intended for leisure and competition, while leaving the main place of residence to participate in sports, watching sports competition, or to visit the sports tourism attractions (Gibson, Attle, \& Yiannakis, 1998). Hallmann, Feiler and Breuer (2012) mentioned that water sports tourism is an activity where the travel motive could either be participating or watching._Gibston (1998) pointed out that sports tourism can be defined as a leisure based tourism which allows people to temporary leave their home range, to engage, spectate physical activity, or visit the sports attraction.

Economic development is a community driven process where communities identify and initiate their own solutions to economic, social and environmental issues to built healthy, economically viable communities (Community Economic Development Canada, 2015). Increasing the quantity and quality of jobs available in community and ensuring that local residents are hired are the common objectives as well as having a greater access to basic consumer goods and services (Cordero-Guzman and Auspos, 2008).

The socio-cultural impacts of tourism describe are the effects on host communities of direct and indirect relations with tourists, and of interaction with the tourism industry. The interaction of the two groups will be a major issue in affecting the types of impacts. Burns and Holden (1995) mentioned that 'when there is large contrast between the culture of receiving society and the origin culture, then it is likely that the impacts will be greater. 
A lake ecosystem includes biotic (living) plants, animals and micro-organisms, as well as abiotic (non-living) physical and chemical interactions. Lake ecosystems are a prime example of lentic ecosystems. Lentic refers to stationary or relatively still water, from the Latin lentus, which means sluggish. (Conroy, Kane, Quinlan, Edwards and Culver, 2017). Lake ecosystems are made up of the physical, chemical and biological properties contained within these water bodies. Lakes may contain fresh or salt water (in arid regions). They may be shallow or deep, permanent or temporary (Hairston Jr. And Fussmann, 2002).

Pollution occurs when the natural environment cannot destroy an element without creating harm or damage to itself. The elements involved are not produced by nature, and the destroying process can vary from a few days to a thousand years. In other words, pollution takes place when nature does not know how to decompose an element that has been brought to it in any way (Conserve Energy Future, 2016). Environmental Pollution is any discharge of material or energy into water, land or air that causes or may cause short-term or long-term effects to the Earth's ecological balance or that lowers the quality of life (O. Coker, 2004).

\section{RESEARCH METHODOLOGY}

The primary data will be collected on the site setting through interviews and observation. As mentioned by Trochim (2006), the essential idea is that the researcher goes "into the field" to observe the phenomenon in its natural state. As such, it is probably most related to the method of participant observation. It is believed that by using qualitative approach, it will give a significant result on the issue that is investigated. The research population is among the community and authority figure at Kampung Melayu Sri Kundang. A total of 5 respondents is selected from the village. The data collection took two weeks.

Data collected will be evaluated by content analysis. Content analysis is a research technique uses to make replicable and valid interferences by interpreting and coding textual material. By systematic evaluating texts, qualitative data can be converted into quantitative data. By using content analysis, it would be more accurate to organize to indicate the respondents' stances on the interview questions. The locals will be interviewed, and data were collected from their answers.

Validity in qualitative research means "appropriateness" of the tools, processes, and data. Whether the research question is valid for the desired outcome, the choice of methodology is appropriate for answering the research question, the design is valid for the methodology, the sampling and data analysis is appropriate, and finally the results and conclusions are valid for the sample and context. This study focuses on the sample group of authority figures at Kampung Melayu Sri Kundang who have the knowledge regarding Tasik Biru Kundang. Trustworthiness in qualitative methodology is establishing these four factors which are credibility, transferability, confirmability and dependability. Based on credibility, the study has a sample size of five respondents which makes the findings true and accurate. The transferability factor refers to the similarity of the research with other researches which could be applicable to other context, circumstances and situation. Confirmability on the research is based on the differences of background between the respondents which remains its neutrality in the research findings. Dependability of the research would have meant that other researchers would have enough information if they were to replicate this study.

\section{FINDINGS \& DISCUSSIONS}

\subsection{Demographic}

The list of participants' profiles shown on Table 1 shows the data for the respondents who took part in this research. Based on the data, there are five respondents who took part with the interview. The respondents' compromises of four (4) males and (1) female. The imbalanced 
number of genders is due to the expertise and knowledge of the area given by the participants. All participants are Malay.

There are three categories of age ranges which are 30-40, 41-55 and over 55. There is one respondent with are age ranges of 30-40, two respondents with the age ranges of 41-55 and three respondents with the age ranges of over 55 years old.

There are three level of education that are present within the respondents which are secondary, diploma and bachelor's degree. Two of the participants had a level of secondary education, two participants had a diploma and one respondent had a bachelor's degree.

Table 1 Summary of Participants' by Demographic Characteristic

\begin{tabular}{|l|l|c|c|}
\hline \multicolumn{1}{|c|}{ Characteristic } & \multicolumn{1}{c|}{ Category } & Frequency & Percentage (\%) \\
\hline Gender & Male & 4 & 80 \\
\hline & Female & 1 & 20 \\
\hline Age & $30-39$ & 1 & 20 \\
\hline & $40-55$ & 2 & 40 \\
\hline & Over 55 & 2 & 40 \\
\hline Education Level & Secondary & 2 & 40 \\
\hline & Diploma & 2 & 40 \\
\hline & Bachelor's Degree & 1 & 20 \\
\hline Race & Malay & 6 & 100 \\
\hline & Others & 0 & 0 \\
\hline
\end{tabular}

\subsection{Local Community}

The result from the findings shows that the respondents highlighted that the development of Tasik Biru Kundang would benefit the local community based on economic factors and image of the village. As mentioned by the respondents;

"The development can help the local community in so many ways such as income and image" "As a restaurant owner, I think that a development of Tasik Biru Kundang will help most of the businesses in and around the village."

As mentioned by Aref et. al. (2010) a community refers to a group of individuals living or working within the same geographic area with same cultures or common interests. Based on the findings, the community in the village strive towards achieving a common interest in order to create a better future for themselves. Local community can play a pivotal role towards the development because if they come to a consensus regarding the development, they could act as a driving force for the development. As mentioned by Haukeland (2011), Jamal and Stronza (2009), if the community have a common interest regarding the development such as economic development, image enhancing, increasing activities and other opportunities, they could make it happen by influencing themselves towards the scenario.

\subsection{Economic Development}

Based on the findings, it shows that all five respondents agreed that the development of Tasik Biru Kundang will encourage economic development in Kampung Melayu Sri Kundang. Respondents also mentioned that the growth of economic development could encourage the locals to start up their own businesses that would lead to potential employment. Only one respondent had a negative outlook as the respondent believe that there would not be as much of a significance towards the economic development in the village. As mentioned by the respondents; 
"The development would definitely help with the economic development of the village. As it stands now, most of the local community gets their income from their small businesses such as restaurants."

"Economic development will grow, from businesses to employment. Most business owner would see the development as an opportunity for themselves because they know that people will come to the village."

The respondents also mentioned that the younger generation in the community could learn and develop their skill towards the business opportunities in the village in order to ensure the village's stability towards the future. These younger generation lacks the experience and knowledge regarding businesses and nurturing them for the future is the best step forward.

From an economy perspective, the primary purpose of community economic development is stimulating local job creation and aggregate business activity. Increasing the quantity and quality of jobs available in community and ensuring that local residents are hired are the common objectives as well as having a greater access to basic consumer goods and services (Cordero-Guzman and Auspos, 2008). Respondents have mention the importance of creating employment through local businesses. They also mention the importance of creating jobs for the community in order to encourage growth for the village.

\subsection{Socio-Cultural Impacts}

For socio-cultural impacts, all respondents agreed that there will be a culture change within the community and the change is inevitable because as the times goes by, ideas and perception will change by the community. They also mentioned that the culture change will fully affect the younger generation as a way for them to adapt towards the future. Few respondents mentioned the importance of social media for their businesses as a way to attract customer to their restaurants. The respondents also mentioned that the development will change the social life of the local community as they hoped that safety precautions for the local community will be tighten in order to avoid any unnecessary illegal activities from the increasing number of visitors entering the village to visit the lake. Most respondents are concerned for their children as they could be easily influenced by the actions of the visitors entering the village to visit the lake. There are respondents who felt that the potential increasing number of visitors could be beneficial for restaurant business in the village which could increase the household income. Respondents also mentioned that the local community could enjoy the scenery and activities as a new developed area.

As mentioned by Burns and Holden (1995), 'when there is large contrast between the culture of receiving society and the origin culture, then it is likely that the impacts will be greater'. From what is mentioned by the respondents, this statement resonates with the comments that is given by the respondents as the culture will change when people are coming to the village.

\subsection{Ecosystem}

For the ecosystem status of Tasik Biru Kundang, there is an unanimous response from all five of the respondents stating that the status of the nature and habitat of the lake is good with some respondents following up by stating that parts on the sides and edges which is not developed have seen their form of degrading. Most of the respondents mentioned that the conditions of the lake has change since the development of the lake in 2012. Before the development, most of the lake was at its natural state with no disturbance from any man-made structure but after the development, most of the areas has to be maintained from the agriculture to the landscaping around the lakeside of the area. Most of the areas around the 
lake which are undeveloped are mostly deteriorated. Most of the deteriorated area are only soil and dead grasses. Respondents mentioned that;

"The condition of the area has stayed the same over the years. Probably after the development in 2012, the condition of the plants has gotten better as they have been maintained. I'm not quite sure of the plants at the undeveloped area on the far end of the lake."

"The condition had change a bit after the development that was done in 2012. Before 2012, the condition of the lake has maintained because most activities consist of swimming and fishing. After the development, most of the natural plants has detioriate and had to be maintained by fertilizers in order to keep them living."

Despite these comments, all of the respondents had mentioned that the condition of the lake compared to 10 years ago had become more attractive. Regarding the potential concerns regarding the ecosystem of the lake, all of the respondents mentioned that water is the main concern because it has a direct influence on the activities and it could play a major factor in the status of the fishes in the lake.

As mentioned by Ricketts (2001) and Alberti (2005), urban development has the effect of decreasing, fragmenting, and isolating natural patches by altering the size, shape and interconnectivity of the natural landscape. This related with the comments made by the respondents as when they mentioned that the 2012 development plays a major part in changing the outlook of the lake while deteriorating aspects surrounding the lake.

\subsection{Environmental Pollution}

From the findings, the respondents have mentioned that pollution is not a problem for the lake because any forms of potential problems such as garbage dealt with immediately._Air pollution is also a problem for the lake as the community is nearby to the highway and the fumes that is given out by incoming cars and jet ski could influence the condition of the air quality surrounding the area. Noise is another pollution respondents have pointed out as noise from cars, motorbikes and jet skis are giving off an unpleasant sound to the community. The main concern for the lake from the development is the water and air quality. Noise could also be another problem from the development because it depends on the number of jet skis that are brought into the lake. As mentioned by respondents;

"My concern is the frequent usage of jet skis because that is the main concern for the lake. It could cause a noise problem for the community, the air will slowly be contaminated from the fumes and the condition of water will change from the potential fuel and oil leakages from the jet skis."

"The potential pollution is the water and air. Water can be affected because all of the activities is done on the lake and that could potentially degrade the quality of water."

Garbage is always a problem for the lake and it could also be a major potential pollution for the lake. If garbage is not well maintained, there might be an issue with the quality of soil in the area. If there is a leakage from the garbage, it will lead to the soil and contaminating the quality. One of the respondents mentioned that;

"Probably the most common pollution around the lake is rubbish. Most visitors and other young locals always leave their trash such as plastic bottle, tin cans and cigarette buds lying around the sidewalk of the lake."

There is still a problem with garbage in the area and this is the fault of visitors and human factor. Respondents have said that visitors in the area needs to take the responsibility to throw their own garbage in order to reduce the load of garbage along the walkway of the lake. 
As mentioned by Debarteleven (1992), environmental pollution and degradation are serious problem as it effects soils and vegetation. Kan (2009) added that environmental pollution can cause problems such as air pollution, water pollution and soil pollution which a community could be exposed to health risks. In order for these pollution to be avoided at Tasik Biru Kundang, proper measures needs to be taken during and after the development in order to minimize the risks of pollution in the area.

\section{RECOMMENDATIONS}

The first recommendation is to establish a motorized water sports such as jet skis on the weekend. With this recommendation, a time slot will be made open for this activity to make sure that there is a very low effect towards the water and air condition of the lake. The best time spot that is appropriate is every Saturday and Sunday at $3 \mathrm{pm}-6 \mathrm{pm}$. This time slot will only be available for motorized water sports to enter the lake.

Jet skis will have the most significance towards the lake because it runs on fuel and motor oil. Any leakage from those will not be friendly towards the condition of water and the environment surrounding the area. As mentioned in the previous chapter, water, air, noise and soil pollution are the most concerning regarding all the community in the area. With a proper time, slot added into the schedule, the community will know the time when jet skis will be used at the lake.

The second recommendation is a non-motorized water sports such as canoeing, kayaking, water paddling and zorbing. These types of water sports could be available anytime throughout the week as it is operated using manpower. By having these water sports available throughout the day, visitors can enjoy the thrill of their own to handle these activities.

Unlike jet skis, these water sports are not operating under machinery as they will have less impact towards the condition of water and air. This type of sporting activities will bring in visitors and at the same time will not have a significant change on the environment and ecosystem. Canoeing, kayaking, water paddling and zorbing are all operated using manpower thus, they could be operated every day of the week.

\section{LIMITATIONS AND FUTURE RESEARCH}

This study has provided the outline of the potential development of a lake based on the factors of local community, ecosystem and environment pollution present in the scope of research. However, there were a few limitations for this research. The first limitation was the findings were generalized in one area. Due to the scope of study is only at Kampung Melayu Sri Kundang, the data cannot be used for other sites. The second limitations were the interviews as the respondents weren't comfortable stating the negative aspects of the village and the had to be ensure that their identities were not mentioned throughout the research.

Future research could be done to access the appropriate sports for the development. A study could be made to look at the aspects of motorized and non-motorized water sports and their appropriateness towards Tasik Biru Kundang. Another study could be made by tackling one of each of the factors to make a further assessment regarding the development of Tasik Biru Kundang such as taking pollution and making it into an individual research on the factors affecting the development. 


\section{REFERENCES}

[1] Coedero-Guzman H., Auspos P92008)., Community Economic Development and Community Change, Retrieved From: http://www.baruch.cuny.edu/mspia/faculty-and-staff/documents/6Chapter4-Cordero-ARCC-07.pdf

[2] Coker A. O., 2004, Environmental Pollution: Types, Causes, Impacts and Management for the Health and Socio-Economic Well-Being of Nigeria, Department of Civil Engineering, University of Ibadan

[3] Ertuna B., Kirbas G., 2012, Local Community Involvement in Rural Tourism Development: The case of Kastamonu, Turkey, Revista de Turismo y Patrimonio Cultural, Vol 10, No 2, P. $17-24$.

[4] Gibson H., Attle S.P., (2018), Segmenting the active sport tourist market: A life-span perspective, Journal of Vacation Marketing https://doi.org/10.1177/135676679800400105

[5] Guneralp B., McDonalds R. I., Fragkias M., Goodness J., Marcotullio P. J., Seto K. C., 2013, Urbanisation Forecasts, Effects on Land Use, Biodiversity, and Ecosystem Services, Urbanisation, Biodiversity and Ecosystem Services: Challenges and Opportunities: A Global Assesment.

[6] Hairston Jr N. G., Fussmann G. F., 2002, Lake Ecosystem, Encyclopaedia of Life Sciences, Macmillan Publishers Ltd

[7] Safura Binti Ismail, 2015, Social Impacts of Tourism Development on Local Community in Mukim Kedawang, Langkawi Island, Universiti Sains Malaysia 